\title{
HAICAI, TABACO E SAQUE \\ (A Poesia de Santôka e o Regresso ao Coração do Poema Japonês) ${ }^{1}$
}

Valdinei Dias Batista

Tudo se aperfeiçoou de Homero em diante, mas não a poesia.

LEOPARDI

La fraternité n'est pas un mythe.

LAUTRÉAMONT

RESUMO: O texto discute o poema haicai do ponto de vista do gênero, utilizando-se, para isso, da definição de Hegel (na Estética) dos gêneros (épico, lírico e dramático). Aborda, assim, dois momentos da história do haicai: o haicai clássico de Bashô (de tendência épica) e o haicai moderno de Santôka (de tendência lírica).

ABSTRACT: The text discuss about the poem haikai by the viewpoint of genre using, for this purpose, Hegel's definition of genres (epic, liric and dramatic, in Aesthetic). It aproaches, so that, two moments of haikai's history: classic haikai by Bashô (which trends to epic) and modern haikai by Santôka (which trends to liric).

PALAVRAS-CHAVE: Poética, Estética.

KEYWORDS: Poetics, Aesthetic.

1. Este texto, que serviu de base a uma palestra proferida na Secretaria de Cultura e Esportes da Prefeitura de Ribeirão Pires em 19 de abril de 1997, é uma humilde homenagem à memória do Prof. Teiiti Suzuki, grande responsável pelo interesse despertado em mim pelo poema japonês, em meus estudos sobre poesia. 
O marco inicial da divulgação, entre nós - brasileiros -, do gênero poético conhecido aqui por haicai é a publicação do livro Trovas Populares Brasileiras, da autoria de Afrânio Peixoto, em 1919.

Afrânio traduz a palavra haicai, desconhecida entre nós, até então, por epigrama lírico, definindo-o como poema formado por "tercetos breves, versos de cinco, sete e cinco pés, ao todo dezessete sílabas. Nesses moldes - prossegue Afrânio - vazam, entretanto, emoções, imagens, comparações, sugestões, suspiros, desejos, sonhos... de encanto intraduzível"2. Essa definição de haicai é o que nos basta para o que interessa ao tema deste trabalho: epigrama lírico.

Em sua obra Estética, precisamente no volume sobre a poesia, o filósofo alemão Hegel nos ensina que o epigrama é a forma mais simples de exposição épica. Além disso, não obstante seu caráter exclusivo e imperfeito, dada sua abstrata condensação, "consiste em extrair do mundo real e da riqueza dos seus fenômenos passageiros um objeto substancial, independente e necessário, para o exprimir em termos épicos"3.

Desse modo, o epigrama nos diz apenas o que a coisa é, sem imprimir uma apreciação subjetiva do objeto indicado. É como a lápide colocada sobre a sepultura, que nada nos explica sobre o indivíduo falecido, nos diz tão-somente: aqui jaz.

Hegel, ainda na mesma obra, nos diz que a épica, ou o gênero épico, "descreve [...] uma façanha, em todas as suas fases, assim como os caracteres donde dimana, quer na sua gravidade substancial, quer nos seus aventurosos encontros com acidentes e acasos exteriores, donde resulta um quadro do objetivo na sua própria objetividade"4 O poeta nos apresenta o mundo épico como um rapsodo que, de maneira mecânica, nos recitasse de cor, nos narrasse um conteúdo na forma de "uma realidade cerrada, independente dele enquanto sujeito, como uma realidade estranha com a qual não se deve identificar a ponto de com ela formar uma unidade subjetiva"s.

É claro que se pode objetar, no que concerne ao haicai, que essa não é uma forma poética que exponha o mundo propriamente objetivado, à maneira do rapsodo aludido por Hegel. Não é por outro motivo que Afrânio o denominou "epigrama", porém "lírico"6

Tomemos, entretanto, como exemplo, a título de ampliação da discussão, um haicai que faz parte do diário de viagem de Bashô - Oku no Hosomichi (Sendas de $O k u)$.

2. Afrânio Peixoto, Trovas Populares Brasileiras, publicado em 1919.

3. Hegel, Estética - Poesia, trad. Álvaro Ribeiro, Guimarães Editores.

4. Idem, p. 120.

5. Idem, ibidem.

6. Encontramos na obra de Ôka Makoto, The Colors of Poetry - Essays on Classic Japanese Verse, duas referências ao assunto. A primeira de Donald Keene, no prefácio ao livro (p. 11): "O haiku é efetivo por causa de sua justaposição de imagens, que criam contrastes surpreendentes e tensões; o waka é geralmente lírico, transmitindo direta ou indiretamente as emoçōes do poeta". E outra do próprio autorpoeta Ôka Makoto, também ela contrapondo o caráter em geral lírico do waka (ou tanka) ao caráter em geral épico do haiku: "Enquanto o haiku pode ser chamado cristalização de instantes fugidios, pode-se chamar o waka ou tanka de interminável corrente lírica de sentimentos e pensamentos experimentados na vida do dia-a-dia". 
Em sua viagem, após atravessar a passagem de Shirakawa, passar pelo rio Abukuma, bordear a lagoa dos Reflexos, Bashô chega à pousada do rio Suga. Procura por um certo senhor Tokyu. É Bashô quem nos diz:

A primeira coisa que fez ao ver-me foi perguntar-me: "Como atravessou a Passagem de Shirakawa?" Na verdade estava desassossegado por viagem tão longa e o corpo tão cansado como o espírito, e além disso com a riqueza da paisagem e tantas lembranças do passado a me perturbarem e me impedirem de ter a paz necessária para a concentração. E no entanto:

Ao plantar o arroz

cantam: primeiro encontro

com a poesia.

Ao dizer-lhe estes versos, agreguei à guisa de comentário: “Impossível passar por aí sem que fosse tocada minha alma"'

O haicai composto por Bashô tem uma motivação lírica (e nesse sentido a denominação epigrama lírico de Afrânio Peixoto se justifica, ao menos pela metade): ao passar próximo às plantações de arroz o espírito conturbado e cansado do poeta se alivia com o canto dos camponeses no trabalho de plantio de arroz - encontra, pois, a poesia na viagem narrada, pela primeira vez. Contudo, o referido encontro é expressado de maneira necessariamente épica (ou, na definição proposta por Hegel, epigramática): o poeta ou rapsodo "recita" maquinalmente a matéria; descreve o acontecimento, a peripécia, para utilizar uma expressão aristotélica. Não é por outro motivo que o rapsodo Bashô agrega o comentário: "Impossível passar por aí sem que fosse tocada minha alma”, um apêndice lírico à narração épica.

A maneira pela qual o haicai é lavrado, burilado ou, em outras palavras, a "cena" que nos é mostrada (o campo de plantio de arroz, os camponeses cantando canções ao ritmo do trabalho) produz no leitor uma comoção: a imagem do trabalho produzindo o alimento (o arroz, base da alimentação japonesa), ao mesmo tempo que a poesia (alimento para o espírito) ${ }^{8}$.

Entretanto, isso não é dito ou sequer esboçado no poema: as imagens e idéias são lançadas em dois blocos: de um lado os camponeses plantando e cantando (o trabalho e a arte) e do outro o primeiro encontro com a poesia (a comoção pela fruição da arte).

Distante do modo lírico ${ }^{9}$, o poeta não faz transbordar seu sentimento, sua comoção (mesmo porque, se lembrarmos as palavras de Hegel sobre o epigrama, o tamanho do poema, bem como os laços dessa forma poética impedem um transbordamento

7. A tradução deste trecho foi tomada do volume Sendas de $\hat{O} k u$, traduzidos do espanhol (da tradução do mexicano Octavio Paz) por Olga Savary.

8. No poema Babel e Sião de Camões, podemos ler:

Canta o segador contente,

E o trabalhador, cantando,

O trabalho menos sente.

9. Em "Crítica, Razão e Lírica: Ensaio para um Juízo Preparado sobre a Nova Poesia no Brasil", Razão do Poema, de José Guilherme Merquior (Rio de Janeiro, Topbooks, pp. 188-189), o autor redefine seu conceito de lirismo, definido anteriormente como "expressão da consciência reflexiva de uma emoção": "Lírico seria o poema onde, em tempo interior, se dá a consciência emocional, a revelação do 
subjetivo), mas, em contrapartida, provoca essa reação no leitor, da mesma forma que Homero procede na narração das aventuras de Ulisses no retorno a Ítaca. A "pintura" sugerida pelo poeta-viajante é seca e delicada.

Em sua obra Os Três Livros, em que fala sobre a atitude e o espírito do haicai, Bashô diz que essa forma poética, para alcançar a beleza, deve, sem artifício mas com espontaneidade, criar o brilho e a delicadeza. Por outro lado, percebemos que o poema haicai do tempo de Bashô (responsável pela modificação do sentido do haicai, de cômico - simples jogo de salão - a real obra-de-arte), propõe uma atitude em dois blocos nocionais, esperando do leitor a reconstrução do seu nexo. A atitude épica (a descrição mecânica) é do poeta (seja ele Bashô, Buson, Shikaku ou Santôka). A comoção é tarefa para o leitor, que deve reconstituir o sentimento da personagem que age no poema.

Podemos agora resumir o que sabemos e deveremos reter sobre o haicai para que sigamos adiante. É um epigrama, ou seja, essencialmente épico, pois não permite que transpareça um $e u$ que se coloque subjetivamente no discurso poético. É formado por uma cadeia de 5-7-5 pés, em geral formado por dois blocos nocionais que exigem do leitor sua decodificação. Deve, ainda, quanto a seu espírito e sua atitude, criar, sem artificialidade, brilho e delicadeza.

Quem pode ser no mundo tão quieto, Ou quem terá tão livre o pensamento, Quem tão experimentado e tão discreto, Tão fora, enfim, de humano entendimento, Que, ou com público efeito ou com secreto, Lhe não revolva e espante o sentimento, Deixando-lhe o juizo quase incerto, Ver e notar do mundo o desconcerto?

Luís Vaz de Camões

Alfredo Bosi, em O Ser e o Tempo da Poesia nos lembra que tanto a épica como a lírica expressam um tempo forte (social e individual) já adensado o suficiente para ser resgatado pela memória. A Poesia exprime um tempo cíclico, corpóreo, denso em sua frase concreta; exibe, por outro lado, o tempo partido da história social afetada pela divisão do trabalho e do poder. A partir desse entrechoque de tempos, o poeta pode, então, criticar o poder, a divisão, a reificação do mundo.

mundo como mágico. Faltou à minha definição uma maior amplitude; faltou dar maior ênfase ao fator linguagem no seu nível de superação - precisamente - emocional. Embora estivesse consciente da extraordinária importância da forma no gênero lírico, ainda assim poderia, aprofundando o seu alcance, acentuar o fato de que na própria linguagem reside uma vontade ordenadora, uma disciplina da emoção. De modo que, se a linguagem pode ser utilizada para comunicar emoções, talvez mais fielmente ainda pode ser instrumento de comunicar a atividade ordenadora do espírito. Há uma emoção em bruto, ou do poema composto como veículo da emoção em bruto: o lirismo pindárico, de raio, profecia, arrebatamento e inspiração. Mas existe uma lírica, de não menor relevo, cuja emoção, mais tranqüila, aparece como memória, como algo recollected in tranquility, ou simplesmente como vibração humana diante do puro ato de interpretar o mundo". 
A poesia, de Bashô - no Japão - e mesmo a de Camões (de época anterior à de Bashô, em Portugal) ou a poesia barroca, exprime em definitivo o que já previa Platão em A República: o poeta estava já definitivamente expulso.

Nos tempos de Bashô já se podiam sentir as forças do capital e a maneira pela qual a vida social se organizaria daí por diante. Podemos observar no conto Shisei (Tatuagem), de Tanizaki Jun'ichiro como era aquele tempo "em que os homens ainda possuíam a nobre virtude da futilidade [...]", tempos em que "o mundo era então mais fácil", tempos em que "os belos eram sempre os mais fortes e os feios os mais fracos. Não havia, portanto, quem não procurasse ser belo. Para consegui-lo tatuavam o corpo e era com orgulho que exibiam a pele enfeitada de linhas e cores vivas e deslumbrantes" Podemos perceber nesse mundo em que a beleza fora relegada a um plano epidérmico, um gosto crescente pela vida mundana: um tempo em que se passará a cultuar valores financeiros e valores físicos, preponderantemente.

Nascido, em 1644, em Ueno, 40 quilômetros distante da antiga capital Quioto, Bashô parte, em 1671, para Edo, então sede do governo central. Teiiti Suzuki nos informa que, por essa época Edo se encontrava em febril expansão:

Cresceu de um vilarejo com 2.000 habitantes no começo do século [XVII] para uma aglomeração urbana espantosa que contava com mais de 800.000 habitantes, resultado do afluxo de gente de todas as partes ${ }^{10}$

Apesar da popularidade crescente, a escola que abrira (Sôin) entra em decadência: o haicai cai na pura comicidade e na extravagância supérflua que o transforma numa espécie de maneirismo" ${ }^{11}$ Vários poetas buscam uma saída para o impasse, inclusive Bashô. Este procura uma saída mudando seu próprio estilo de vida: retira-se em 1680 para uma chácara à beira do rio Sumida. Em 1682 o incêndio que destruiu Edo não poupa sequer a cabana do poeta: ele se abriga na casa dum discípulo na província de Kai e a partir de então passa a maior parte do tempo em peregrinação. Entra para a estirpe dos poetas itinerantes.

É certo que essas peregrinações têm como objetivo precípuo divulgar sua escola, a nova mentalidade que deseja imprimir ao haicai, mas mesmo isso decorre - além da peregrinação, da necessidade de não se fixar em lugar algum - do desencantamento com a nova ordem social ${ }^{12}$. Resolve, perambulando, sua estética ${ }^{13}$. Morreu em viagem, em 1694, em Osaka.

10. Teiiti Suzuki, in Revista de Estudos Japoneses, vol. II, São Paulo, CEJ/USP, 1982.

11. "A escola de Sôin entra, porém, em rápida decadência: a busca desenfreada de comicidade e de novidades cada vez mais extravagantes leva o movimento à anarquia e aos caos" Teiiti Suzuki, "Bashô e sua Poética", in: Estudos Japoneses, vol. II, São Paulo, CEJ/USP, 1982.

12. Qualquer semelhança com Luís Vaz de Camões e o Desconcerto do Mundo não seria mera coincidência. Veja-se o poema Ao Desconcerto do Mundo: "Os bons vi sempre passar/ No mundo graves tormentos;/ E pera mais me espantar,/ Os maus vi sempre nadar/ Em mar de contentamentos./ Cuidando alcançar assim/ O bem tão mal ordenado,/ Fui mau, mas fui castigado./Assim que, só pera mim/ Anda o Mundo concertado". Na verdade, é o mundo do Capital se erguendo e ditando a nova ordem: a ordem burguesa.

13. Para Bashô, o haicai é um constante exercício espiritual e a viagem é a melhor escola para esse exercício: viajar é fugir da vida sedentária, é desprender-se, desapegar-se, despojar-se. 
Com Bashô e seus seguidores, discípulos, podemos dizer que o haicai atinge seu clímax nesse período. A Bashô podemos, portanto, antepor o epíteto clássico no sentido definido por Eliot: clássico é todo artista que esgota a linguagem de seu tempo, à perfeição. Não obstante essas mudanças sociais a que vimos aludindo até aqui, à poesia de Matsuo Bashô ainda coube o privilégio de se expressar de maneira epigramática (ou épica, naquela acepção dada ao termo por Hegel). Deixamos, agora, o Japão Clássico e adentramos o Japão da era Moderna: veremos que, a Santôka, impõe-se o modo lírico.

\title{
III
}

\author{
Vou-me embora pra Pasárgada \\ Lá sou amigo do rei \\ Lá tenho a mulher que eu quero \\ Na cama que escolherei.
}

Manuel Bandeira

A era Meiji (1868-1912) representou para o Japão uma época de profundas transformações políticas, econômicas e, principalmente, sociais. Pode-se dizer que fundou um novo país, agora se organizando sob os ideais de um Estado Moderno e a caminho da hegemonia do Capital ${ }^{14}$. A era Meiji põe fim não somente a séculos de feudalismo, mas obriga uma civilização - após mais de 200 anos de isolamento quase completo - a encarar as mudanças inerentes ao mergulho no mundo moderno, ou seja, à era do Imperialismo ou, como querem alguns, do Capital Avançado.

O novo rumo político-econômico assumido representa o triunfo da democracia liberal sob a liderança do Estado. A partir daí, a sociedade se centrará no poder burguês dos grandes centros, será abolido o sistema de classes até então vigente, em nome do individualismo e do humanismo (se é que podemos falar em humanismo em tempos de Imperialismo).

As dificuldades em se assimilar essa nova ordem econômica, social e política poderá ser sentida, com mais agudeza, sem qualquer dúvida (e por motivos evidentes) na literatura.

Santôka, cujo verdadeiro nome era Taneda Shoichi, objeto deste trabalho de ora em diante, nasceu no vilarejo de Sebare, próximo a Yamaguchi, em 3 de dezembro de 1882, ou seja, 14 anos após o início da era Meiji, no cerne mesmo da transformação.

Filho de um proprietário de terras na prefeitura de Yamaguchi, depois de abandonar o curso de Letras na Universidade Waseda motivado por um colapso nervoso (1910), o pai lhe arruma um casamento, montando com ele uma fábrica de saquê, indo ambos à bancarrota em 1916. Santôka começara a escrever haiku em 1911, como discípulo de Seisensui.

Separa-se da esposa em 1920, tentando - inutilmente - vários empregos. A partir de 1926 vaga pelo Japão, como monge mendicante, por 8 anos, fazendo uma ermida 
em Yamaguchi (1932) e outra no templo Miyukidera. Terminou a vida peregrinando e bebendo. Era o ano de 1940.

Como se vê, sua vida foi, ela também, marcada por essas mudanças profundas por que passava o Japão (e lógico, o mundo). A mãe se suicidara aos 33 anos (Santôka tinha então 11 anos), atirando-se, na presença do futuro poeta, num poço.

Certa noite, bêbado, parado sobre a linha do trem, quase morre atropelado. É salvo por um monge budista e se converte ao budismo. Santôka, assim como Bashô, Rôtsu e Issa, descobre na peregrinação valor estético para sua Arte.

Por outro lado, o contato com a literatura estrangeira já então comum entre os jovens literatos, além da procura da liberdade individual (fortemente influenciada pela ideologia liberal recém-importada), leva Santôka e seu grupo de poesia, denominado Nova Tendência, a proporem o abandono da forma clássica de composição, desobrigála da métrica, da utilização da palavra de estação (kigo), em favor dessa forma completamente livre: o haicai deve ser, nesse novo Japão e para esses novos rapazes, uma poesia liberta de toda regra que não seja a justa tradução da experiência poética ${ }^{15}$. Para Seisensui o haicai como gênero poético é a poesia capaz de plasmar um estado momentâneo intenso e puro, bem como percepções transcendentalmente importantes.

Para Santôka, a poesia é "pura experiência" "Tudo o que não esteja realmente presente no coração não constrói o haiku" $O$ haiku, que roça a superfície das coisas, deve também fazer sentir o indizivel profundo da experiência humana, apreendida na eternidade do instante presente. Nesse sentido, haiku e zen são indissociáveis. A poesia de Santôka, escrita em linguagem simples, é o reflexo das coisas e dos eventos os mais cotidianos possíveis, os mais comuns, aqueles aos quais a consciência rotineira não presta qualquer atenção.

"A sabedoria está em ver o novo no ordinário, em acomodar-se ao mundo tal qual é. Há tesouros ocultos no instante presente." Por isso fala muito em saquê: essa bebida representa um meio privilegiado para se colocar num estado de disponibilidade e de abertura para com o mundo que condiciona a experiência poética.

O saquê para o corpo,

o haiku para o coração.

O saquê é o haiku do corpo,

o haiku é o saquê do coração.

Por outro lado, assim como o meio social de Bashô determinou mudanças em seu modo de vida, e, por conseguinte, em sua Arte, o mundo social de Santôka determinou mudanças de igual ordem em sua vida e estética.

Se por um lado o mundo em que vive Santôka (lembrar que sua obra foi escrita praticamente no período entre as duas grandes guerras) lhe impôs o rompimento com a rigidez das regras clássicas, inspirado em idéias liberais em tudo semelhantes ao simbolismo francês e ao modernismo em geral, por outro determinou um retorno às formas arcaicas da poesia japonesa: livre das amarras a diç̧ão de Santôka pôde resgatar,

15. Lembrar o verso de Bandeira: "Não quero mais o lirismo que não seja libertação" 
como dizia Alfredo Bosi, o tempo forte, contraposto ao tempo social partido e evocar a essência do poema japonês de todos os tempos: a matéria poética em si.

Buscando o simples, o cotidiano, o comum, numa linguagem também ela simples, despida de rebuscamentos artificiais, o poema de Santôka expõe a experiência humana ela mesma, livre da determinação do tempo. Vemos por aí que, à poesia de Santôka, impõe-se um caráter mais lírico que à de Bashô: este ainda conseguiu se exprimir em tom épico; Sântoka se valerá da expressão lírica de que falava Merquior (v. nota 9, p. 103-104) "uma lírica [...] cuja emoção, mais tranqüila, aparece como memória, como algo recollected in tranquility, ou simplesmente como vibração humana diante do puro ato de interpretar o mundo", diferente do transbordamento sem freios.

Em resposta ao ingrato tempo presente - lembrando, ainda uma vez, Alfredo Bosi - o poeta mitifica o prosaico, o comum, o vulgar, ressacralizando a memória mais profunda da comunidade. $O$ poeta recompõe, assim, otempo inteiriço, o universo mágico que o tempo presente rechaça. A poesia pode ser, agora, a experiência do prosaico epifânico, o saquê, o tabaco, a cuia de arroz. Santôka reencontra, finalmente, no cerne da sua comunidade, o coração da poesia. É isso, agora, o haicai.

IV

Caminante, no hay camino,

Se hace camino al andar.

Antonio Machado

Assim como para Bashô, também para Santôka a viagem é uma descoberta estética. Viajando a pé pela solidão das estradas é que o poeta compreende verdadeiramente as pessoas, a poesia, a natureza; em suma, é viajando que o poeta reencanta o mundo.

Mas como pode dar-se isso, se, durante a viagem o ser humano Santôka precisa conviver com a solidão, a dor, a carência e a possibilidade da morte?

A morte à minha frente;

um vento fresco.

Minha morte,

a relva, a chuva.

Esses haicais nos mostram que, se por um lado a morte é uma possibilidade durante a aventura da viagem solitária, ela está lado a lado com a natureza: $o$ vento fresco, a relva, a chuva. A morte não seria assim um acidente, mas um continuum com a vida, e mesmo uma conseqüência. A dor, por seu turno, é não só uma consequiência, mas um aprendizado:

Na relva

exponho ao sol

as feridas da viagem. 
Dou pancadas nas moscas

Dou pancadas nos mosquitos

Dou pancadas até mesmo em mim.

No primeiro haicai o poeta expõe as feridas ao sol sobre a relva, não como uma coleção de medalhas com que tenha sido condecorado, mas como passos do aprendizado que, em forma de cicatrizes, poderão segui-lo durante o resto de sua vida como sinais, reavivamento da memória.

O segundo haicai, como que explica o primeiro: assim como para espantar o incômodo causado pelos insetos, o poeta os afugenta com pancadas, afugenta o que o incomoda a si mesmo, infligindo-se a dor (a viagem, o despojamento): é o caminho do zen - expulsar de si tudo o que não seja humano. O budismo já dissera que tudo é dor e a dor surge do desejo de se não sentir a dor jamais: o zen é o retorno a si mesmo, o osso sem carne, o haicai sem ornamento.

Tusso sem parar

Ninguém para me dar tapas nas costas

O corvo crocita;

também eu estou só.

Acendo o fogo do solitário.

Esses poemas nos põem em contato com a solidão do poeta durante a peregrinação. Mas não há nessa exposição qualquer rancor, nem qualquer soberba, queixa ou lamento, como sentimos, por exemplo, nos poemas dos românticos. No tom cômico (e por isso compreensivo) do primeiro poema podemos perceber uma simples constatação da condição humana: o poeta engasga e não há ninguém por perto para lhe dar tapinhas nas costas - tem de se valer por si mesmo. Ou a constatação de sua própria natureza solitária no simples ato de acender a fogueira. No diálogo com o corvo, a solidão do poeta se rende à naturalidade:

O corvo crocita;

também eu estou só.

O poeta descobre numa voz da natureza a essência do ser humano. Nesse sentido, ao se irmanar com a natureza, o poeta-monge (ou o monge-poeta) descobre também aí a lição zen: penetra na solidão mais completa do ser humano. Não obstante, a solidão existe mas não o perturba, como as ondas num lago perturbam o reflexo, contudo, não podem perturbar a lua.

Sem albergue onde pernoitar;

a lua desvela o caminho.

Aqui, não obstante o fato de não encontrar durante a viagem um lugar para o descanso, o espetáculo do caminho iluminado pela lua serve como um bálsamo para as 
feridas do caminho. Novamente o zen: o fazer sem finalidade, continuar a caminhar sem perturbação porque o caminho é feito à medida que se caminha, como no poema de Antonio Machado.

Esses exemplos nos mostram o que significa a viagem para Santôka: é a experiência, é o aprendizado sem finalidade, o não apego, o despojamento. É, ao mesmo tempo, uma experiência estética que lhe dá a dimensão formal do haicai: a liberdade brotando da experiência viva presente. $O$ fazer por fazer: a vida sem finalidade. A arte tem de ter caráter similar.

\section{Uma libélula}

pousa sobre meu chapéu de bambu.

Caminho.

A caminhada sem pausa e sem finalidade é tão lenta e sem perturbações que dá tempo ao inseto de pousar no chapéu do viajante. Pode-se tomar esse haicai como exemplar da estética de Santôka: nada deve perturbar a experiência poética: métrica, vocábulos, tradições.

A viagem permitiu a Santôka que pudesse ter acesso à própria alma do povo japonês e descobrir que essa arte, a arte do haicai, é viva e sua vida deve brotar do coração do seu povo.

Em vários haicais, entretanto, a viagem, a peregrinação, não se traduzem somente em dor, restrição ou solidão. A viagem sendo despojamento consentido, sofrimento buscado que produz consciência - como reza o budismo mais castiço - e, mais que tudo, componente estético para sua Arte, tem por tudo isso seus momentos de prazer e deleite.

\section{Completamente nu}

exposto ao sol.

Lá onde o azul do mar é sem fím.

Toda a viagem sem palavras.

$\mathrm{O}$ ruído das ondas.

\section{Apertam-se com vigor}

tua mão, minha mão rachadas.

Podemos imaginar o viajante cansado, esgotado da peregrinação, deitando-se, nu, sobre a relva, sentindo na pele o calor dos raios de sol. Quase que se pode sentir a mesma sensação experimentada pelo poeta. O poema se parece com o longo poema Canto a Mim Mesmo, do americano Walt Withman: lá o poeta deitado sobre a grama, braços e pernas abertos, descobre que possui - num abraço - o mundo todo. Aqui, o prazer de descansar exposto nu ao sol mostra ao lírico que ele, como o poeta americano, pode ser livre e possuir o mundo.

Isso é patente no poema seguinte: 
Lá onde o azul do mar...

A viagem, como a busca de si mesmo e a da liberdade, é sem limites, sem fim, como o azul do mar que, simulando seu fim na linha do horizonte, na verdade mascara sua ausência de limite. Mais uma vez a poesia desmascara a realidade ao nomear o mundo.

A solidão da viagem, por sua vez, nem sempre é pura ausência:

Toda a viagem sem palavras.

$\mathrm{O}$ ruído das ondas.

A ausência de palavras pode preparar a percepção para ruídos que o falar costuma encobrir, senão desconhecer. Acostumado ao silêncio da peregrinação, surge o prazer de ouvir o ruído das ondas do mar, como se fossem vozes distantes se comunicando com o poeta.

A ausência de companhia, por outro lado, preenche-se de alegria ao deparar com a solidão amiga: o companheiro, também peregrino, também com as mãos rachadas pelo frio. No vigor do aperto de mãos, nota-se o calor das solidões companheiras.

Epílogo

Eu preparo uma canção que faça acordar os homens e adormecer as crianças.

Carlos Drummond de Andrade

Este trabalho teve por nome Haicai, Tabaco, Saquê.

Vimos até aqui as idéias de Santôka a respeito da poética haicai, que pode ser resumida com o vocábulo experiência. Já dissemos que fica entrevisto nesse conceito a ligação com a experiência zen, que busca o indizível, uma experiência arisca à expressão verbal.

Para Santôka, o saquê era um meio de atingir um estado de disponibilidade desse momento. Mas era mais: era o calor nas noites de frio das viagens solitárias, bem como, por ser um vinho obtido da fermentação alcoólica do arroz - cereal representativo da própria cultura japonesa - tem para Santôka essa conotação sagrada que o vinho de uvas terá para um cristão convicto ${ }^{16}$.

Sem saquê, consternado,

contemplo a lua.

Tenho o que comer

Tenho com que me embriagar.

A relva sob a chuva.

16. “Um homem que só bebe água tem algum segredo para esconder dos seus semelhantes”, nos diz Charles Baudelaire em seu texto sobre o vinho. 
No primeiro poema, a ausência do saquê, num momento de tristeza. Mesmo sem o filtro sagrado, o olhar do viajante se perde na contemplação da lua: como milhares e milhares de homens em outras eras já fizeram. A lua de Santôka é a mesma lua de Bashô, de Sôra, de Issa, de Busson" ${ }^{17}$.

Também aqui, o espírito da contemplação atinge o coração da comunidade como se estivesse num outro tempo, num tempo fora do tempo, numa outra dimensão em que todos os que contemplaram a lua com a alma exposta vivessem o mesmo momento, sincronicamente. Daí a lembrança do saquê: o vinho que carrega esse conteúdo cultural em seu sabor, seu efeito e sua fabricação (é fruto do trabalho de plantio - lembrar o haicai de Bashô, na primeira parte deste texto - colheita, fermentação e envazamento: como o poema, é trabalho coletivo).

O segundo poema nos mostra dois momentos do prazer culminando na Arte: a fome saciada, a disponibilidade poética ativada - a experiência poética é atingida.

Tenho arroz, tenho livros, tenho até mesmo tabaco.

Na tabacaria sem tabaco cai uma chuva fina.

Santôka dizia que lhe bastavam poucas coisas na vida: um quarto, lâmpada, mesa, banho, saquê. Se possuía dinheiro, durante as viagens comprava saquê, tabaco e cartõespostais. O saquê, como vimos, lhe dava disponibilidade para a experiência poética, esquentava as frias noites solitárias. Os cartões-postais serviam-lhe para enviar seus poemas a jornais e amigos. O tabaco era aquele momento de ação no ócio, que nos falava Mário Quintana: "O fim do cigarro tem uma tristeza de fim de linha", "O cigarro é uma maneira disfarçada de suspirar"

Além disso, podemos lembrar a conotação de embaçamento, enevoamento, aquela atmosfera de indefinição que se alia à imagem da fumaça em momentos da história da poesia como o Romantismo (e seus charutos e spleen). Para Santôka, o tabaco é tudo isso: o prazer, o ócio, a lembrança das atmosferas indefiníveis, indizíveis, assim como o momento poético: é experiência estética. Mas é, também, remédio contra o tédio, como para os românticos.

Vemos, dessa maneira, que Santôka impôs seu tempo forte, re-descobriu o coração da cultura de seu povo na experiência poética de seu haicai renovado, contemporâneo, rebelde em relação à forma clássica, lírico. Nesses termos, ao se tornar "moderno", contemporâneo a seu mundo, provocou - com sua poética remodelada - um retorno às formas mais arcaicas da matéria poética japonesa. Não um retorno a "fôrmas" antigas,

17. Num poema de Dantas Motta podemos ver idéia semelhante, referente ao sol: " $O$ sol, que nasceu ontem./ é o mesmo de hoje e será o mesmo/ De amanhã, de depois, de depois". Ou então os versos de Fausto Nilo na música de Robertinho do Recife: "Seja o meu céu: [...] O céu azul do meu destino,/o céu de Ícaro e de Galileu./ Céu de coro nordestino./ onde eu e Buñuel./ Constelações do meu cabelo,/ no céu, no céu, no céu" 
mas ao espírito que as produziu, em épocas remotas. Ao espírito da sua cultura, que agora pode produzir uma lírica renovada.

\section{Bibliografia}

BAtistA, Valdinei Dias. "Chiclete com Banana - A Experiência do Haicai no Brasil". Estudos Japoneses, n. 14, São Paulo, CEJ/USP, 1994.

BLYTH, R. H. Haiku. Hokusseido, 1954, 4 vols.

Bosı, Alfredo. O Ser e o Tempo da Poesia. São Paulo, Cultrix, 5. ed., 1986.

FuKUDA, Hideichi. "As Estações do Ano e sua Concepção na Literatura Japonesa". Estudos Japoneses, n. 14, São Paulo, CEJ/USP, 1994.

HegEL, Georg Wilhelm Friedrich. Estética - Poesia, Lisboa, Guimarães Editores.

KeEnE, Donald. Dawn do the West. New York, Henry Holt \& Co., s/d.

MaKoTo, Ôka. The Colors of Poetry - Essays on Classic Japanese Verse. Michigan, Katydid Books/Oakland University, 1991.

Merquior, José Guilherme. Razão do Poema, Rio de Janeiro, Topbooks, 2. ed., 1996.

Motoyama, Shozo. "Ciência, Cultura e a Tecnologia e a Restauração Meiji”. Estudos Japoneses, n. 14, São Paulo, CEJ/USP, 1994.

SANTÔKA. Zen saké haiku (tradução: Cheng Wing Fun e Hervé Collet), Paris, Moundarren, 1990.

SUZUKI, Teiiti. "Bashô e sua Poética”. Estudos Japoneses II, São Paulo, CEJ/USP, 1982.

TAKENAGA, Beatriz Shizuko. “A Divisão Histórica Japonesa”. Estudos Japoneses VII, São Paulo, CEJ/USP, 1987.

TOIDA, Helena Hisako. "Imperador Meiji, sua Época e seus Poemas”. Estudos Japoneses V, São Paulo, CEJ/USP, 1985.

WAKISAKA, Geny. "Chôka - O Poema Longo e os demais Poemas Japoneses”. Estudos Japoneses VIII, São Paulo, CEJ/USP, 1988.

"Sakimori Uta: Poemas de uma Instituição Social-Militar". Anais do III Encontro Nacional de Professores Universitários de Língua, Literatura e Cultura Japonesa, São Paulo, CEJ/USP, 1992. . "Introdução" Contos da Era Meiji, São Paulo, CEJ/USP, 1993.

Yoshimasu, Gôzô. "O Poder da Imaginação Auditiva - de Santôka a Bashô" Anais do III Encontro Nacional de Professores Universitários de Língua, Literatura e Cultura Japonesa, São Paulo, CEJ/USP, 1992. 